\title{
Philosophy, Addiction and Inquiry.
}

\author{
Olav Gjelsvik, CSMN, IFIKK, University of Oslo.
}

\begin{abstract}
This introductory paper raises, partly as a preparation for the other papers in this issue, questions about how philosophy ought to proceed in the light of knowledge we have in surrounding disciplines with a focus on the case of addiction. It also raises issues about how addiction research might be enlightened by philosophical work. In the background for the paper are two competing approaches to the evidential grounding of philosophical insight. According to a widespread view, philosophical knowledge rests on a set of intuitions. According to another, philosophy has no special evidential grounding. This paper will resist the attractions of the first picture, and argue against the separateness of philosophy that it lends support. I shall try to make plausible that such a picture is harmful both for philosophy and for empirical science. We should replace it with a mild form of unity of science or unity of inquiry, in the spirit of the founder of this journal.
\end{abstract}

\section{Introduction}

We have recently seen a development towards a philosophy of philosophy modelled on philosophy of biology, psychology and so forth. It is fair to say that the philosophy of science community has not contributed much to this development; it is rather a development by methodology-conscious philosophers with high general competence but no specific background in the philosophy of science. On the other hand there is, in this development, an acknowledgement of a desire to learn from the way philosophy of science has fruitfully approached various disciplines when turning to the discipline of philosophy.

The question of what philosophy is or ought to be is of course a hotly contested topic, more so than in almost any other discipline. One major aspect of that discussion concerns the evidential basis for philosophical knowledge (if there is such a thing). Disagreements on that point reflect substantive disagreement as to whether philosophy as a discipline is set apart from other disciplines, by for instance basing itself on intuitions and having conceptual insights as its aim, or whether there is no such separateness, and perhaps no such aim as (pure) conceptual insight. Alvin Goldman represents a mild form of the first line and writes, "One thing that distinguishes philosophical methodology from the methodology of the sciences is its extensive and avowed reliance on intuition." 1

\footnotetext{
${ }^{1}$ Alvin Goldman, "Philosophical Intuitions: their Target, their Source and their Epistemic Status", in: Grazer Philosophische Studien 4, 2007, pp. 1-26, p.1.
} 
If we take the view expressed by Goldman literally, we see philosophy as very different from any empirical science, in that the evidential base is largely made up of intuitions. Such a view raises a number of issues, not least issues about what intuitions are, how we know them, whether they carry their evidential status on the surface so to speak, in a manner not unlike Humean impressions or intuitions in ethics. A contrasting view would maintain that intuitions simply are theoretical judgements that can always be revised in the light of further theoretical development. In that case, they have no special evidential role. A third view could be quite agnostic about what intuitions are, and take no reductive stance towards intuitions, but argue case by case that intuitions play no interesting role in establishing philosophical knowledge.

This paper will resist the attractions of the first picture, and argue against the separateness of philosophy that it lends support. I shall try to make plausible that such a picture can be harmful both for philosophy and for empirical science. We should replace it with a mild form of unity of science.

\section{Philosophical evidence and intuitions.}

One extremely general phenomenon that really lends some plausibility to the first picture that gives intuitions an important role, is our limited ability to provide fully informative accounts of general and philosophically central concepts, i.e. the concepts that philosophy is typically interested in, the concepts the exploration of which makes up the core of philosophy. Here we find concepts like justice, cause, knowledge, and explanation. One central theme in the history of philosophy of science has been the development of proper concepts/theories of explanation and also of cause. Take explanation as an example. Many theories/accounts of explanation have been refuted by counterexamples provided in the literature. We might conclude that the counterexamples show that a suggested account or theory of explanation lets in both too much and/or too little, and we hold that this fact refutes that theory/account in question. Thinking about how this insight is established, that the theory is refuted, the ground on which the insight rests, we might think that the counterexample elicits an intuition, and that this intuition is to be thought of as an insight into the concept of explanation that the suggested theory did not capture. When we thus intuit that relevant fact about the concept of explanation, we also realize by the same token that the suggested theory or account of explanation is refuted. Timothy Williamson has developed a careful alternative to this way of thinking in his discussion of the parallel issues in the case of knowledge. Still, many people here see a source for their way of thinking about intuition as the evidential base.

The questions Goldman's view gives rise to include questions about what intuitions actually are, and also whether there is, as a matter of fact, extensive reliance on them in actual philosophical practice. We can frame questions about the logic and semantics of the verb "to intuit" something in order to make progress here, and do all this within the setting of seeing the core of philosophy as the exploration of the contents of a cluster of 
central concepts. Kirk Ludwig has contributed interestingly towards such an understanding of intuition. ${ }^{2}$

Intuitions, however, seem at least very close to judgements about conceptual content, i.e., in our case, the content of the concept of explanation. Whether they are judgements or not is of course the controversial point; if they are judgements they do not necessarily have the sort of special or exceptional epistemological role that they are given on Goldman's view.

There are various grand strategies of arguing against a view like Goldman's. One could argue like Quine against the very distinction between the analytic and the non-analytic. Timothy Williamson has argued for a view that is not different from Quine's regarding the relationship between the analytic and the non-analytic, and in doing so committed himself to far fewer controversial assumptions that Quine did. ${ }^{3}$ Williamson argues both against the metaphysical version of view, i.e. the view that meanings or conceptual content make the analytical truths true, and also against the epistemological thesis that possessing or mastering a concept brings with it knowledge of analytical truths. If no interesting distinction between the analytic and the non-analytic can be upheld, then the picture of the core of philosophy as devoted to the exploration of conceptual truths as something very different from empirical truths cannot be upheld. If this is so, then there is no attraction in the view that the evidential ground on which philosophical knowledge rests is something special and very different from the ground of other kinds of knowledge.

Herman Cappelen's work on intuitions complements Williamson's work. ${ }^{4}$ A main part of it consists in a careful and very valuable investigation into the question of whether philosophers do rely extensively on intuition even when they claim they do. His conclusion is that they do not; they do not rely on intuition in their work in any other sense than that of appealing to theoretical judgements. There is thus a mismatch between what many philosophers do, and their own understanding of how they go about it.

\section{How ought philosophy to proceed?}

Both Williamson and Cappelen seem to me to be basically right in their claims. Still there is an issue about how far they take us in the direction of any normative issue about how philosophy ought to be conducted. Williamson's basic message is that many philosophers' basic conception of their own activity is faulty: they are trying to do something which is in fact impossible when they attempt to achieve insight into the

\footnotetext{
${ }^{2}$ Kirk Ludwig, "Intuitions and Relativity”, in: Philosophical Psychology 23, 4, 2010, pp. 427-445.

${ }^{3}$ Timothy Williamson, The Philosophy of Philosophy. Oxford: Blackwell 2007.

${ }^{4}$ Herman Cappelen, Philosophy without Intuitions. Oxford: Oxford University Press 2012.
} 
conceptual side of a terrain marked by a sharp distinction between conceptual truths and empirical truths. That sharp distinction has been with us from Hume and Kant, and is a present and powerful force. Cappelen's basic message is that philosophers don't do what Goldman claims they do or what they often claim themselves to be doing; they do not in fact rely on intuitions in their arguments or in the way they try to establish their philosophical theses. This is good news if Williamson is right; they are not trying to do the impossible after all even if they think they are. Still little follows directly from Williamson's and Cappelen's writings about 'ought' issues: whether philosophy is in a happy state and ought to follow its present course, or whether it would benefit from clear changes in the way it is conducted. They have, however, prepared the ground for possible changes. As long as there is no special evidential ground that philosophical knowledge rests upon, then what is good for philosophy is simply to answer its questions and do that in the best possible way.

It is within this general perspective that I want to present some specific aspects of the philosophical work on addiction. This is much less of a jump than it might seem at first. The basic lesson I want to draw is that taking in theoretical/empirical results in this area can be surprisingly fruitful for a range of deep philosophical questions that have been with us for centuries, questions that look like conceptual questions. I also want to claim that philosophical engagement with the empirical sciences on an issue like this can be fruitful for how the empirical sciences are conducted, what questions they ask etc. If this is right, it provides some ground for an ought: philosophy ought to concern itself more directly with at least some specific issues in the sciences; that it is good both for philosophy and for the sciences. Progress in philosophy as in many other fields comes in surprising ways. The philosophy of science has examples of a similar sort, but let us focus on this one case.

\section{The significance of addiction.}

Addicts pop up in philosophical discussions, and the concept of addiction has now received quite a bit of philosophical interest. The first example I will point to is Harry Frankfurt's 1971 discussion of freedom of the will. ${ }^{5}$ The addict is there portrayed as someone compelled to consume the addictive substance no matter what. There is 'total' absence of freedom of the will, and the compulsion is so conceived that compelled consumption cannot really be intentional action. Further research has shown that Frankfurt's conception of an addict is much too simplistic, but for the moment we can ignore that point. We have two dimensions in play by bringing addiction into the issues that Frankfurt was working on, or two clusters of issues, one around the concept of freedom of the will or autonomy, and the related concept of responsibility, and also one around the concept of intentional action. The issues around intentional action hook up with conceptions of weakness of the will (or acrasia). Let me also add that it might of

\footnotetext{
${ }^{5}$ Harry G. Frankfurt, "Freedom of the Will and the Concept of a Person", in: The Journal of Philosophy 68, 1971, pp. 5-20. Reprinted many places.
} 
course have been a mistake of Frankfurt to bring in the case of addiction, given his purposes. I shall maintain that it was not. If there was a mistake it was rather that he did not take such phenomena as addiction sufficiently seriously when trying to understand freedom. There is undoubtedly some impairment in freedom of the will when you are addicted to heroin or alcohol, even if the impairment is very different from the way Frankfurt conceived of it. The type of impairment throws important and unexpected light on what freedom of the will is.

There is more. The case of addiction is clearly an area where different scientific disciplines approach the same phenomenon. This is of great interest for many reasons, and it raises, in complex ways, questions about the relationships between the questions these disciplines try to answer. On the one hand we have the decision sciences, and economics, and their ways of providing accounts of addiction, as rational choice in some cases, or as the result of the operation of mechanisms of irrationality understandable only within a choice framework, like hyperbolic discounting, or similar such things. People within these sciences mainly interact with other members of their own discipline. In the biological models of addiction there is a tendency to say this is addiction, and then identify some more or less permanent change in the mesolimbic system or in nucleus accumbens. As it turns out, such permanent neurophysiological changes are far from perfectly correlated with the behavioural patterns that the decision sciences attempt to explain with their approaches; some things thus seem to be better explained by the latter, and knowledge is lost if the whole focus is the former. The relationship between the neurological modelling and the decision-theoretic modelling is, therefore, delicate and challenging, and also marked by limited interaction between the disciplines.

One of the most important results from the addiction research is the basic finding of Berridge and Robinson about the structure of the motivational system. ${ }^{6}$ They claim to have found that motivation in mammals can be seen as two cooperating but dual systems, one system to be thought of as expressed by "wantings", the other by "likings". Likings seem to be cognitively informed, and to be stable the way being cognitively informed is stable. It therefore has many properties in common with judging something to be best, while at the same time it seems to have some motivational elements (this is, however in need of further investigation, and seems somewhat undetermined by data). "Wantings" behave differently, and are directly motivational. The picture is, furthermore, that these

\footnotetext{
${ }^{6}$ Kent C. Berridge, and Terry E. Robinson, "The Mind of an Addicted brain: Neural Sensitization of Wanting versus Liking”, in: Current Directions in Psychological Science 4, 1995, pp. 71-76; Kent C. Berridge, and Terry E. Robinson, "The Psychology and Neurobiology of Addiction: an Incentive-Sensitization View", in: Addiction 95, Supplement 2, 2000, pp. S91-S117; Terry E. Robinson, and Kent C. Berridge, "The Neural Basis of Drug Craving: an Incentive-Sensitization Theory of Addiction”, in: Brain Research Reviews 18, 1993, pp. 247- 291.
} 
two systems normally march in step. The important bit is that they can come apart in special cases where this normal working of the motivational system of the organism is suspended. In those more exceptional circumstances we see cases of liking something and not wanting it, and wanting something and not liking it, to the point of disliking it. Wantings can fluctuate in dramatic ways when circumstances are special. More specifically, being addicted to addictive substances can influence mammals to desperately want things, i.e. wanting to consume a substance, even when they do not like doing it. It is still fair to say that a motivational monism can get pretty far in explaining many of the same things as the dual approach of Berridge and Robinson, and that has been done by introducing mechanisms like hyperbolic discounting in the fashion of George Ainslie. ${ }^{7}$ The fact that there seems to be neurophysiological evidence in favour of the dual approach is extremely interesting and challenging, and judging between these approaches requires a very balanced theoretical judgement that takes in very many concerns, maybe also philosophical concerns.

Let me just stop and take stock at this point and say something about how the findings in this area can be of great help when resolving philosophical issues, and also something about how philosophy can contribute to the ongoing research that should result. I will take the last issue first, even if this order might seem to be getting things the wrong way round.

\section{Benefits from philosophy to ongoing empirical research.}

a) The basic issue of whether the general approach to motivation should be monist or not is an old one in philosophy, and in the philosophical tradition there has been a number of ways the oppositions between such views have been played out. This background seems fruitful and important for the full assessment of the theoretical conflict between dual and monist approaches to motivation. Philosophy can therefore, in this area, be an important contributor to generate hypotheses that can be empirically tested in ways not conceived of in earlier days.

b) Philosophy and philosophy of science can contribute in a number of ways in clarifying and resolving some of the issues around very different disciplines trying to address and explain what looks like the same phenomenon. This is indeed one of the specialities of philosophy: to analyse and settle whether explananda are the same or not, and whether explanations are competing explanations or not. Against this background, philosophy can contribute to the theoretical judgements required for answering whether dual and monist approaches to motivation are indeed competing. There is here a three-way meeting point between neuroscience, behavioural science and philosophy. The best way forward seems to be enlightenment about what the various disciplines and approaches try to do and how they do it.

c) Philosophy, and the philosophy of science as well, can contribute towards seeing and working out the more general significance of some of the findings in the more empirical

${ }^{7}$ Ainslie, George, Picoeconomics, CUP, Cambridge, 1992, and many later writings. 
sciences. The particular benefits might be to work out a new and scientifically informed conception of agency with an informed focus towards how to think of impaired agency, and look at how such a conception matters for the required theoretical judgements about what is impaired in what way, what is not impaired etc. That is now in the process of being done by Richard Holton and Kent Berridge, and of course by many others. ${ }^{8}$ Much of this work will have major repercussions for how to do philosophy of action.

Against the background of such work one might also hope for an account of addiction that clearly exhibits how freedom gets impaired when the addiction develops, and a full theory of addiction might be getting closer. That will bring with it possibilities for major progress for how society deals with addictions, how to think of addicts' responsibilities for their acts, whether they are able to give informed consent for various types of treatments and so on.

\section{Benefits to philosophy from empirical research.}

The possibility of a dual approach to motivation grounded in neurophysiology can be of great help when trying to make progress on some very deep issues in philosophy. Here are some examples:

a) The debate about whether normative or moral judgements are intrinsically motivating (internalism/externalism issues) ought to be informed by such new findings. Much of the discussion in philosophy is simply blind to the possibilities which parts of empirical science now seem to entertain, and very many of the arguments put forward in philosophy will have to be reconsidered in the light of the possibility that we can fail to want things we like (or judge best), and we can like (or judge best) things we do not really want. Traditional justifications of internalism and externalism in philosophy are potentially all in trouble. Let me add that there are further delicate issues here about how close "likings" are to judgements about what is best or right to do in an agent capable of such judgements. The interactions with internalism and externalism issues might actually be a way towards much greater clarity in how to think about likings.

b) How to conceive of acrasia or weakness of the will have to be discussed all over again. This cluster of problems makes up a very old and deep set of issues in philosophy. Many of the arguments against the possibility of acratic action, or weak willed action, from ancient time will have to be reconsidered, partly because they rely on specific internalist conceptions of normative judgement we perhaps cannot uphold in the light of the present findings and the support for the distinction between wanting and liking. There is some vague parallel between the present findings and old theses about partitioning of the soul, and these issues have to be further explored as well. They might throw much light on how we should relate to such thoughts.

c) We also have to reconsider philosophical accounts of compulsion that seem to block conceiving of compulsion as intentional action with some, albeit limited, sort of freedom.

\footnotetext{
${ }^{8}$ The work Holton and Berridge are doing together is not published yet.
} 
This brings in a full range of issues about the extension of the concept of doing something intentionally, what that is, and what the things are that we do intentionally, and the relationships between what we do intentionally and what we are free to do.

d) Another whole area in philosophy that can benefit much from this new knowledge is all the work around the mind-body problem. The various types of dynamic interaction between the neurophysiological level and the intentional level in addictive behaviours is a rich source for new and more concrete ways of thinking about this age-old problem.

e) A further area has to do with developing informed views on addiction which can ground both ethical and legal decisions involving addiction, responsibility of addicts etc. The question I raised above, about whether heroin addicts can give informed consent to be given free heroin in experimental treatment, is a burning question in today's society, and we need, as a society, to be better informed than we are to be able to answer that question.

Final thought: The background outlined seems to me to make possible new and constructive interactions between work in more general philosophy and more specialized work in the philosophy of science, to the mutual benefit of both. The focus on phenomena that are being studied from different disciplines and where the findings can have major implications for philosophy itself seems to be the exactly right focus to bring about new and interesting interactions between philosophy of science and philosophy. To my mind that interaction has suffered lately. Here is a way forward with benefits to all.

\section{Concluding remarks and a normative perspective.}

I set out to provide reasons for a change in the way philosophy is done towards a certain type of interdisciplinarity; towards learning from the empirical sciences in ways relevant both for making philosophical progress and for laying the ground for very constructive interaction between philosophy and the these other disciplines, for the benefit both for all disciplines involved and for society at large.

There is a large number of reasons in support of a quite specific ought. This ought directs towards learning from science, and integrating that learning into the way we do philosophy, instead of trying to elicit the most sophisticated intuitions from armchair philosophy. In many of the areas described above, philosophy proceeds in a traditional way without paying almost any attention to work in various sciences that can actually benefit philosophy, and attempts at actual interactions are at best very scarce. The philosophical work would still mainly be conducted in the same armchair even after a change of ways, but not by calling up intuitions that are to be had in splendid isolation from knowledge of empirical science. It would have to be pursued by two-way interaction with a large number of other sciences and disciplines, with philosophy situated at the theoretical end of the mutually enlightening work. That provides the ground for a good way of doing both many parts of philosophy and some parts of science, and thus provides grounds for an ought-statement to the same effect. If this ought I am defending is a fact, that fact seems fully compatible with seeing intuitions as theoretical 
judgements, and, on the other hand, it is in some clear tension with seeing intuitions as some sort of (independent) evidence.

It is probably fair to say that I have picked an area that is ideal for support for the conclusion I am drawing about how philosophy ought to proceed. Even if this is so, it does not detract essentially from the point that in many areas of philosophy progress is least likely to come from continued traditional efforts where philosophical issues are discussed in complete isolation from relevant neighbouring sciences. These things will actually be somewhat different in different parts of philosophy, but the point here is that concepts/discussions about things like blameworthiness, responsibility, doing something intentionally, being free to do something, internalism versus externalism in approaches to motivation, evaluative concepts etc, are central philosophical issues and have been so for centuries. There can be other parts of philosophy where gains from interdisciplinarity are much smaller than the case of addiction and the related cases. That is, so far, just an open question. I believe there are many cases that support the same general type of conclusion as I have drawn here.

\section{The Significance of the Present Issue.}

This present issue of Inquiry contains papers devoted to various aspects of addiction, and can all be seen as significant contributions to the kind of development that this small article is pushing for. The papers of Heyman, Ainslie and Sugden discuss deep questions at the borderline between philosophy and the sciences, Heyman's contribution is focussed directly on addiction, and brings forward a new view, the other two papers, Ainslie's and Sugden's, bring new and radical views on important surrounding questions. Together they bring three different but very important and very challenging perspectives into view. Jeanette Kennett discusses some of the same foundational issues around addiction, but from the more philosophical side of things, with a view to what a person is. Stephen Morse's paper brings in connections with how addicts's responsibilities is thought of in the law, and thereby builds very interesting bridges in another direction. The more empirical paper by Melberg, Henden and Gjelsvik has one particularly interesting result: even if addictive behaviour to a large extent is seen as the addict's own responsibility among the respondents, that does not in itself effect or reduce the recognized obligation to provide help to the addicts. All papers in all the present issue are examples of the sort of the sort work Arne Næss in his time wanted to see published in Inquiry.

\footnotetext{
* I am very grateful to Nick Allott for comments. Much of the material in this introductory paper is also published in a paper of mine entitled 'Philosophy as Interdisciplinary work', to be published 2013 in a collection in the series 'Philosophy of Science in Europe'.
} 


\section{References.}

Ainslie, George, Picoeconomics, CUP, Cambridge, 1992.

Berridge, Kwent C. and Terry E. Robinson, "The Mind of an Addicted brain: Neural Sensitization of Wanting versus Liking", in: Current Directions in Psychological Science 4, 1995, pp. 71-76.

Berridge, Kent C. and Terry E. Robinson, "The Psychology and Neurobiology of Addiction: an Incentive-Sensitization View", in: Addiction 95, Supplement 2, 2000, pp. S91-S117.

Cappelen, Herman. Philosophy without Intuitions. Oxford: Oxford University Press 2012.

Frankfurt, Harry G. "Freedom of the Will and the Concept of a Person", in: The Journal of Philosophy 68, 1971, pp. 5-20. (Reprinted many places.)

Goldman, Alvin. "Philosophical Intuitions: their Target, their Source and their Epistemic Status", in: Grazer Philosophische Studien 4, 2007, pp. 1-26.

Ludwig, Kirk. "Intuitions and Relativity”, in: Philosophical Psychology 23, 4, 2010, pp. 427-445.

Robinson, Terry E. and Kent C. Berridge, "The Neural Basis of Drug Craving: an Incentive-Sensitization Theory of Addiction”, in: Brain Research Reviews 18, 1993, pp. 247-291.

Williamson, Timothy. The Philosophy of Philosophy. Oxford: Blackwell 2007.

Olav Gjelsvik,

CSMN,

Department of Philosophy, Classics,

History of Art and Ideas

Faculty of Humanities, University of Oslo

Box 1020 Blindern, N-0317 Oslo, NORWAY

olav.gjelsvik@csmn.uio.no 